\title{
BORIS SCHNAIDERMAN: UM CASO DE AMOR PELA LITERATURA ${ }^{1}$
}

\section{Uma entrevista com Boris Schnaiderman}

RESUMO

Nesta entrevista, o tradutor, ensaísta, professor aposentado da Faculdade de Filosofia Letras e Ciências Humanas da USP e fundador do Curso de Russo nessa faculdade, Boris Schnaiderman, fala de tradução e literatura e conta um pouco de sua trajetória profissional.

\section{ABSTRACT}

In this interview, Boris Schnaiderman talks about translation, literature and his own career. Well-known translator and essayist ,he was the founder of the Course of Russian language and literature at Universidad de São Paulo.

\section{PALAVRAS-CHAVE}

Tradução literária; literatura russa; Boris Schnaiderman; cultura russa; curso de língua e literatura russa.

\section{KEYWORDS}

Literary translation; Russian literature; Boris Schnaiderman;

Russian culture; course of Russian language and literature.

\footnotetext{
${ }^{1}$ Publicado originalmente em Caderno de Literatura e Cultura Russa, publicação do Departamento de Letras Orientais (DLO), FFLCH, USP. São Paulo: Ateliê Editorial, março de 2004.
} 


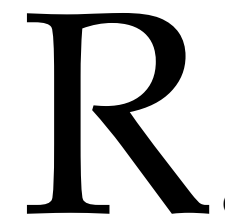

eferência obrigatória quando se trata de cultura e literatura russa, o tradutor e ensaísta Boris Schnaiderman é hoje o maior especialista nessa área, no Brasil. Autor do romance Guerra em Surdina, cuja primeira edição saiu em 1964, começou a traduzir obras de autores russos em 1944 e, desde 1957, publica ensaios na imprensa brasileira. Entre os seus livros de ensaios, estão: Dostoiévski - Prosa Poesia (Perspectiva, 1982), Turbilhão e Semente - Ensaios sobre Dostoiérski e Bakhtin (Livraria Duas Cidades, 1983) e Os Escombros e O Mito - A Cultura e o Fim da União Soviética (Companhia das Letras, 1997). Por meio das suas traduções, o público brasileiro entrou em contato com grandes nomes da literatura russa como Dostoiévski, Púshkin, Tchékhov, Górki e outros.

Professor aposentado da Faculdade de Filosofia, Letras e Ciências Humanas, Boris Schnaiderman fundou o curso de russo da USP em 1960. Com coragem e determinação, enfrentou as dificuldades impostas pela ditadura e manteve o curso aberto, inclusive no período de maior repressão. ${ }^{2}$

P. O senhor nasceu em 1917, em Úman, na Ucrânia, e veio para o Brasil com oito anos. Quais são as suas lembranças da infância?

R. Da infância, guardo muitas recordações, inclusive da cidade em que passei minha primeira infância, Odessa. Fui levado para ali quando tinha um ano. Era época de grande turbulência na Rússia, início da guerra civil, massacres, principalmente de judeus, e como sou de família judia, os meus pais resolveram partir para Odessa. Isso é uma longa história. Em linhas gerais, posso dizer que as impressões da minha primeira infância foram muito fortes, num país em guerra civil, onde havia fome e desorganização.

Quando eu tinha 8 anos, viemos para o Brasil. Os meus pais passaram por muitas dificuldades, inclusive financeiras. Quando chegou a época da faculdade, optei pelo curso de agronomia, que concluí aos 23 anos. Portanto, sou engenheiro agrônomo, ou, melhor, prefiro dizer que eu era engenheiro agrônomo, pois deixei tudo isso completamente de lado.

\footnotetext{
2 Suprimimos o parágrafo que dizia, que, o professor Boris dedicava-se, quando do momento da entrevista, "à revisão de traduções antigas", que estavam sendo relançadas pela Editora 34, e à revisão de seu romance, Guerra em Surdina, para nova edição. Além disso, o tradutor e ensaísta atendia com frequência a convites para palestras e mesas-redondas.
}

184|BORIS SCHNAIDERMAN: Rodapé 
Mas exerci a profissão durante alguns anos. Fui agrônomo de carreira do Ministério da Agricultura.

Sempre quis me ocupar de literatura.

Fiz o curso de agronomia por pressão da família.

P. E quando fez a opção pela tradução?

R. Sempre quis me ocupar de literatura. Fiz o curso de agronomia por pressão da família. Naquele tempo, só havia três profissões consideradas válidas para um jovem de classe média: médico, engenheiro ou advogado. Já existia a Faculdade de Filosofia de São Paulo, mas diziam que isso era coisa para moças casadoiras, não para um homem, que precisava ter uma profissão.

P. Como venceu esse preconceito?

R. Bom, devido às circunstâncias, não é? Devido às circunstâncias... Como já disse, sempre quis me ocupar de literatura. Inclusive depois de iniciada a carreira de agrônomo, eu fazia traduções. Eu tinha uma dificuldade muito grande, queria fazer literatura, queria escrever em português, mas no caminho do meu português estava sempre o russo. Eu achava que o russo me atrapalhava, dificultava o meu trabalho. Mas hoje em dia é difícil dizer se dificultou ou se enriqueceu, é tudo junto - riqueza e dificuldade.

Eu precisava ganhar a vida e durante muito tempo não pude exercer a profissão de agrônomo porque, na época do Estado Novo, havia a exigência de que o indivíduo, para exercer uma profissão liberal, devia ser já naturalizado e ter feito serviço militar. Então providenciei a minha naturalização. Mas não foi fácil. Durante o Estado Novo, o simples fato de eu ser russo dificultava tudo; um russo que queria se naturalizar brasileiro era como um estigmatizado.

Também fiz o serviço militar. Poderia ter feito o serviço militar na assim chamada linha de tiro de guerra, tipo de serviço militar mais brando. Optei pelo serviço militar num quartel e acabei indo para a guerra. Foi uma experiência muito rica e muito importante para mim.

P. No romance Guerra em Surdina, descreve a sua participação na guerra. Em que contribuiu essa experiência para a sua relação com a literatura e a tradução?

R. O contato com gente do povo me ajudou muito. Na verdade, tive contato com brasileiros das mais diversas camadas sociais. Tive companheiros que eram altos funcionários do Itamarati, um companheiro que estudava 
engenharia, outro medicina... Participei da guerra como calculador de tiro e, por isso, estive no meio de gente de maior escolaridade.

A experiência foi muito rica e procurei transmiti-la no meu livro Guerra em Surdina, do qual acabei de preparar uma quarta edição revista, que será lançada em breve. Com o tempo, percebi que era necessário tratar a literatura de modo mais familiar. Esse livro me ajudou muito nisso. Fiz um esforço para deixar o estilo um tanto empolado das minhas traduções da época. Fiz o que era possível na época, mas, relendo agora, verifico que ainda há uns trechos muito empolados, muito solenes. Por isso a revisão. O livro, como um todo, me agrada muito, realmente é alguma coisa que me é muito cara.

P. Nele, o senhor trata da questão da brutalização do ser humano, mas, no final, parece ter havido uma experiência humanizadora, pelo menos no seu caso em particular.

R. É algo muito complexo. Quer dizer, não foi por ter lido Guerra e Paz que escrevi o romance. Foi por ter vivido aquilo e ter procurado expressar da minha maneira. Eu concordo com Tolstói. Numa carta, ele diz que só tem valor aquilo que é criado, não adianta, simplesmente, colocar a experiência no papel. Claro que ele disse isso por outras palavras, de maneira muito mais articulada, mas a essência é a seguinte: não adianta ficar apenas descrevendo experiências pessoais; isso e testemunho, crônica. Literariamente, só tem valor aquilo que é criado. A experiência pessoal serve como tema, porém esse tema também poderia ser algo inventado. No meu caso, tive a vivência do tema.

Ontem (30.11.2002), o grande diretor de teatro russo Aleksandr Sokúrov realizou um debate extraordinário com o público no Cine SESC. Entre outras coisas, ele disse: "Eu gosto de fazer documentário, mas o que eu faço, o filme que eu faço não é a vida. Quando faço um documentário, não retrato simplesmente a vida, crio algo mais, que é o próprio documentário". Documentar, aliás, segundo a concepção dele, é muito relativo porque sempre há esse fato cria-se outra vida. Dostoiévski, quando escreveu Recordações da Casa dos Mortos, não estava simplesmente retratando, ele estava criando com base na própria experiência.

No meu caso, a experiência pessoal foi importante, mas a criação resultante foi mais importante. O romance é outra coisa, não é mais a vida cotidiana. Como disse Sokúrov, "o meu filme não é a vida".

A verdade é que não se pode ditar um caminho para a arte. $A$ arte tem os seus próprios caminhos, o seu próprio desenvolvimento, a sua própria riqueza. 
P. Entramos, então, na questão da interpretação da realidade, o que me faz lembrar o realismo socialista.

R. A questão do realismo socialista... O que houve de ruim, de péssimo, de viciado, de detestável foi o fato de quererem instituir o realismo socialista como a única doutrina, a única teoria, a única literatura válida e aceitável. Dividiam a literatura em realismo crítico e realismo socialista. Realismo crítico era o que os escritores russos faziam antes e o que os escritores de países burgueses estavam fazendo naquele momento... Enquanto isso, na Rússia, só era válido o realismo socialista.

A verdade é que não se pode ditar um caminho para a arte. A arte tem os seus próprios caminhos, o seu próprio desenvolvimento, a sua própria riqueza. Apesar disso, o realismo socialista deixou alguma coisa boa, algumas poucas obras realmente válidas do ponto de vista da criação.

Um exemplo bastante significativo é o romance Don Silencioso, de Mikhail Chólokhov. Não se pode negar a importância dessa obra. Aliás, a tradução do título em português não expressa bem o título russo. $O$ original é Тихий Дон (Tíkhi Don). O adjetivo, Тихий (tíkhi), quer dizer "silencioso", mas também significa algo de suave, é um termo carinhoso. Era dessa forma que os cossacos se referiam ao rio Don, mas não queriam dizer simplesmente que ele era tranquilo, queriam expressar carinho e afeição. A tradução para o português refletiu apenas um sentido da palavra original. Esse sentido é o mais corrente nos dicionários, mas não é o único.

P. Talvez a escolha tenha sido infeliz.

R. Na verdade é difícil... O tradutor tem de escolher um sentido e, de uma língua para outra, é uma dificuldade enorme. Os franceses conseguiram traduzir: muito bem o título, eles traduziram como Le Don Paisible. Paisible é "pacífico", mas também é "tranquilo", "suave". Essa questão da tradução de títulos é muito interessante, a boa tradução de títulos é uma arte. Vou dar alguns exemplos de traduções que foram de uma felicidade incrível. Os tradutores, em certos casos, souberam expressar o sentido do original de maneira admirável.

Há um romance do Somerset Maugham que, em inglês, é chamado The Moon and Sixpence, literalmente, "A Lua e Seis Tostões". O penny corresponde a menor moeda na Inglaterra, então poderíamos usar "seis tostões", não é? Ou então alguns traduzem por dinheiro - "seis dinheiros", mas essa é uma tradução feia. No francês, foi traduzido de um jeito horrível. Não traduziram o título, pegaram o sentido do texto e criaram Benvouté. O romance trata da vida do grande pintor francês Gauguin no Taiti. Então, The Moon and Sixpence representa o sonho e o cotidiano. Gauguin era um bancário, abandonou o emprego e a família para viver no Taiti, ou seja, abandonou Sixpence pelo sonho, pelo delírio até. A tradução francesa tem um título muito prosaico. L'envouté significa alguém que está 
enfeitiçado, recolhido, aprisionado; alguém que fica fascinado por alguma coisa. Nesse caso, não faz muito sentido.

E como é que traduziram para o português? O tradutor fez um achado notável - Um Gosto e Seis Vinténs. Quer dizer, ele suprimiu aqui a metáfora da lua, mas deu um toque bem no espírito da língua portuguesa. Ficou excelente.

Quer ver outro? Há um romance utópico do Aldous Huxley que se chama em inglês Brave New World. É uma citação de Shakespeare. Foi traduzido como Admirável Mundo Novo. Com esse exemplo podemos ver por que a tradução não deve ser literal. Brave seria bravo, valente... Embora se tenha perdido a citação de Shakespeare, a solução do tradutor foi muito feliz.

Às vezes, é difícil traduzir um título. Na minha experiência, tive dificuldades. Por exemplo, um dos volumes da trilogia autobiográfica de Máximo Górki se chama В людях (V liúdíakh). O que é esse В людях? Literalmente seria "no meio das pessoas", "no meio de gente". Mas em russo a conotação mais comum é a de uma pessoa que já se fez, uma pessoa que já se formou, não no sentido escolar, mas já se formou paraa vida. Nesse caso, aproveitei o título de uma tradução francesa. Traduzi esse volume da trilogia de Górki e chamei-o de Ganhando Meu Pão. Mas não é original; digo isso em uma nota, aproveitei o título francês. $O$ fato é que essa solução expressa muito bem o sentido, porque, se você for traduzir literalmente, não consegue transmitir todo o sentido do original. $O$ tradutor francês teve uma ideia muito feliz.

Outro exemplo da minha própria experiência é o título de um conto de Tchékhov, no original Попрыгунья (Poprygúnia). Literalmente, é aquela que pula, aquela que salta, mas isso tem uma relação com a fábula da cigarra e da formiga, traduzida para o russo por Krylov. Achei difícil traduzir o título, mas, no Enel, acho que consegui uma boa solução. Traduzi como "Ventoinha", porque o sentido é esse - uma pessoa Saltitante, que vira pra todos os lados.

Aqui nós chegamos ao cerne de um problema importante. A tradução nunca é transposição direta de palavras. Isso é uma noção consagrada. Horácio já escreveu sobre isso. Há uma carta de São Jerônimo sobre a sua tradução da Bíblia (muito criticada então por se afastar do sentido literal) em que ele defende a opinião de que a tradução nunca pode ser literal. A tradução literal resulta nas maiores bobagens. Tem-se de transmitir o espírito do original. Não adianta ficar implicando - ah, traduziu assim, traduziu assado, não está muito correta. A crítica tem de ser feita, mas o que se traduz é o espírito, não é o texto, não são as palavras nem as frases. O que se transmite é o espírito do texto, essa é a verdadeira fidelidade. 


\section{[Na tradução] O que se transmite é o espírito do texto, essa é a verdadeira fidelidade.}

P. A tradução seria então, como o senhor próprio afirmou em uma entrevista no Estado de S. Paulo, o rigor aliado à criação?

R. Exatamente. O rigor aliado à criação. Rigor tem de haver, mas com liberdade. É um problema dialético. Tem de haver rigor e tem de haver liberdade, tem de haver criação.

P. Um bom exemplo seria o trabalho de tradução que o senhor realizou juntamente com os irmãos Campos.

R. Ah, sim. Eles tiveram achados formidáveis. Vou dar um exemplo. O Haroldo tem uma tradução do poema "Definição de Poesia" (Определение поэзии), de Pasternak. Um dos versos desse poema foi traduzido pelo Haroldo da seguinte forma: "A dor do universo numa fava". É um verso belíssimo. É mais bonito do que o do original russo. Mas o Haroldo sempre justifica isso da seguinte maneira: a tradução segue a lei das compensações. Num trecho eu vou expressar menos do que o autor expressou. Então tenho de recuperar em alguma outra parte.

P. Nos últimos anos, no Brasil, as editoras têm publicado várias traduções de obras russas, inclusive de sua autoria. A que atribui esse aumento do interesse pela literatura russa?

R. Podemos falar dessa questão, do interesse pela literatura russa no Brasil. A partir do século XX houve um grande interesse motivado pela curiosidade. Todo mundo estava percebendo que na Rússia aconteciam coisas importantes. Politicamente, havia um interesse muito grande e houve também o impacto do interesse dos franceses pela literatura russa. Esse maior interesse do público francês pela literatura russa estava ligado a vários fatores. Em primeiro lugar, penso eu, devido à aproximação russofrancesa, em consequência do jogo entre as potências. A França, que havia sido derrotada na guerra franco-prussiana, sentia-se ameaçada pela Alemanha. Dentro da França havia um grande movimento pela revanche, queriam retornar a Alsácia e a Lorena e faziam outras reivindicações nacionalistas. Os alemães estavam muito atentos a isso. Existia, portanto, essa tensão. Para encontrar um aliado, a França aproximou-se da Rússia. Isso foi no começo da década de 1880. Além disso, os franceses encontraram na literatura russa uma visão que se contrapunha àquele positivismo científico, às vezes muito imediatista, e que estava dominando o Ocidente. E a literatura russa oferecia algo muito diferente. Escritores 
como Tolstói e Dostoiévski ofereciam algo diverso. Isso causou um impacto.

No Brasil, por contaminação, também houve um interesse muito grande. Lia-se muito literatura russa, mas sempre em francês, em espanhol... Quando apareciam traduções, geralmente eram traduções indiretas. Depois houve um interesse muito grande pela Revolução de 1905 e, mais tarde, pela de 1917. Os brasileiros acompanharam muito de perto o que estava acontecendo na Rússia. Quase sempre por via indireta, mas acompanharam. Esse interesse manteve-se até mais ou menos 1945, com o fim da Segunda Guerra Mundial. Depois disso, veio o período da Guerra Fria. Naquela época, o mercado brasileiro foi inundado por obras secundárias, pelo que havia de pior no assim chamado realismo socialista. Eram obras de pura exaltação, que afastaram o público.

Em 1958, aconteceu o escândalo Pasternak e o romance desse escritor tornou-se uma sensação. O Doutor Jivago foi traduzido às pressas em todo o Ocidente. Por isso, uma retomada do interesse inicial. Mas a obra era muito complexa para o leitor comum.

Outro fator importante foi o lançamento dos Sputinik russos, mas esse interesse não chegou a se refletir na recepção da literatura, pois havia essa imagem negativa, o público estava meio afastado da literatura russa. Havia aquela admiração pela Rússia, pelos feitos espaciais russos etc., mas isso não foi suficiente para despertar um novo interesse pela literatura.

Esse interesse eu estou notando de uns três anos para cá. Acredito que haja vários fatores para isso. Há o fator de que a literatura russa tem um material riquíssimo a transmitir e estava bastante fora de circulação. Publicaram muito nas décadas de 30 e 40, mas de modo geral a literatura russa estava fora de circulação no Brasil. Muita coisa que era divulgada no Ocidente não chegava aqui. Agora está chegando. E há o fato de que apareceram tradutores do russo, apareceram e não foram poucos.

\section{Na literatura russa, há muitas obras importantes que deveriam ser traduzidas para o português. Inclusive na literatura do período soviético.}

P. Talvez agora seja possível apresentar ao público brasileiro obras e autores russos que ainda não foram divulgados no Brasil. Quais seriam as obras ou autores russos mais importantes, ainda desconhecidos do público brasileiro?

R. Púchkin está relativamente pouco divulgado. De Liérmontov existe a tradução do Paulo Bezerra, O Herói do Nosso Tempo, mas há muitas obras 
importantes que não foram traduzidas. Da obra de Turguêniev, por exemplo, foi traduzida uma parte mínima. Górki... Havia um grande interesse por Górki no passado, hoje em dia foi posto de escanteio, o que é uma injustiça, ele é um grande escritor.

$\mathrm{Na}$ literatura russa, há muitas obras importantes que deveriam ser traduzidas para o português. Inclusive na literatura do período soviético. Um escritor como Zóchtchenko - realmente um grande escritor dos primeiros anos após a Revolução. Dele existem no Brasil apenas alguns contos isolados em antologias e também uma coletânea feita pela Tatiana Belinky.

Outro exemplo é o escritor Iúri Oliecha, grande escritor. Dele eu só traduzi uma novela, Inveja. Mas ele tem obras importantes. Recentemente, saiu um diário seu. Ele havia publicado em vida alguns trechos de diários, mas agora saiu um mais completo. Ao que parece, ele estava guardando esse material, não era para publicar em vida. Na Rússia também há maior divulgação de Oliecha.

Por exemplo, há um escritor do período soviético que até hoje quase não foi divulgado no Brasil. Numa ocasião, traduzi um continho dele para a revista da USP, uma coisa bem acidental. Daniil Kharms. Realmente é um grande escritor. Fez uma literatura do absurdo na Rússia da segunda metade da década de 20. Portanto, é um percursor de Beckett, de Ionesco. É um escritor muito forte. Eu soube que uma estudante de pós-graduação de russo esteve traduzindo Daniil Kharms.

Mas, enfim, são muitas as obras que deveriam ser traduzidas. Não se traduziu um trabalho importante do Tchékhov, que é o livro A Ilha de Sacalina. Não está traduzido.

Das obras autobiográficas de Górki se traduziu muito pouco. Da prosa de Óssip Mandelschtam, grande poeta, vítima do stalinismo, que durante muito tempo, não foi publicado na Rússia, apareceram recentemente dois trabalhos em prosa, traduzidos pelo Paulo Bezerra - $\mathrm{O}$ Rumor do Tempo e Viagem à Armênia. Mas ele tem outras obras em prosa muito importantes. Por exemplo, o livro Conversa sobre Dante é um ensaio extraordinário. Até hoje não foi publicado em português.

Outro exemplo: Varlam Chalamov. Contos dele saíram publicados em Portugal. No Brasil, que eu saiba, ele não foi publicado até hoje e é do grupo dos escritores que saíram do Gulag, que escreveram sobre o Gulag, na minha opinião é o mais forte deles.

De poesia russa, haveria muita coisa para traduzir. Basta dizer que a obra fundamental, que é Evguiéni Oniéguín, de Púchkin, não tem tradução em português. Nós estamos muito atrasados em relação a outros países, principalmente em relação aos países de língua espanhola. Em compensação, em alguns casos, temos traduções melhores que as dos espanhóis. A tradução de poesia no Brasil atingiu um nível muito alto. Há 
certa tradição nisso. Inclusive na geração anterior à nossa. As traduções de Manuel Bandeira, por exemplo, são magníficas. Isso é reconhecido mundialmente. Mas, em termos de quantidade, ainda estamos muito atrasados.

P. Vamos aproveitar esse passeio pela literatura russa para voltar à sua carreira como tradutor. Quando o senhor começou a publicar traduções do russo?

R. Comecei a publicar traduções do russo no ano de 1944. Eu me dediquei bastante às traduções do russo naquela época, sempre com pseudônimo. Sentia que não estava suficientemente maduro. E realmente não estava. Quando pego as minhas traduções daquele tempo, vejo muitos defeitos.

Um defeito é o fato de que eu não fazia cotejo. O cotejo é indispensável. A pessoa fez uma tradução do russo, depois tem de pedir a alguém que leia a tradução do texto e ela fica conferindo em russo. Para repensar o texto e também para evitar as eventuais distrações. Todo mundo se distrai. Não há quem não se distraia. Por mais que se corrija, por mais que a gente lide com o texto, a distração aparece. Não existe tradução perfeita, mas o que se pode é diminuir a percentagem de erros. E eu não fazia cotejo. Não percebia a necessidade disso. Pra mim, hoje em dia, isso é questão essencial. Não existe tradução literária boa sem que se faça cotejo.

Mas, voltando à minha carreira, eu precisava ter um ganha-pão, inclusive depois de estar trabalhando como engenheiro-agrônomo, precisava completar a renda com traduções. Em 1959, saiu a primeira tradução assinada por mim. Mais uma vez eu não fiz cotejo. Só depois dessa primeira tradução é que eu passei a fazer cotejo.

Nas minhas traduções, vejo três fases bem delimitadas. A primeira fase é essa das traduções que eu assinava com pseudônimo. Depois, vieram as assinadas com o meu próprio nome, traduções que sempre estavam ligadas a um cotejo do texto. Dessa forma, foi possível melhorar o texto. Mas, ao mesmo tempo em que o melhorava, também incorria num defeito muito grave. Eu tinha um respeito muito grande pelo texto literário, uma admiração muito grande, e, com isso, minha produção se tornava muito solene. Havia um excesso de solenidade. É o que noto nas minhas traduções, por exemplo, da década de 1960. Existe uma ou outra um pouco mais solta, mas, em geral, eram solenes. Só bem mais tarde eu passei a me controlar mais, procurar um estilo mais solto, despojado. Isso só recentemente, a partir da década de 1990, eu posso dizer. Por isso é que, com frequência, publico traduções revistas. Faço revisões das minhas traduções da década de 60 . Preciso refazer aquelas traduções, quero deixar um acervo de obras no nível que estou exigindo hoje de mim próprio. 
P. Como o trabalho acadêmico passou a fazer parte da vida do agrônomo e tradutor?

R. Aconteceu o seguinte. Em 1960, principalmente na fase da euforia com o lançamento dos Spútnik e das tentativas de aproximação com a Rússia, houve da parte da USP o interesse pela instituição do curso de russo. Eu soube disso, apresentei minha candidatura e fui aceito. Eu já havia publicado na imprensa trabalhos sobre literatura russa. Comecei a publicar trabalhos na imprensa em 1957. E o primeiro livro de minha autoria é de 1964 - a primeira edição de Guerra em Surdina. Então, aí você vê que foi um caminho bem áspero. Superei dificuldades.

Na USP, o curso foi iniciado em 1960 como curso livre de língua e literatura russa e depois, em 1963, foram instituídos os cursos de línguas orientais. A partir daí o curso de russo passou a ser um curso regular na Universidade, com concessão de diploma e tudo o mais. Nós tivemos uma dificuldade muito grande com a situação política. Em 1964, houve o golpe e o curso de russo recebeu várias investidas. Na Maria Antônia, foram invadidas salas de aula. Professores foram espancados, batiam nos professores, batiam nos alunos.

Eu ficava muito indignado, muito revoltado. E, na primeira vez em que houve invasão da minha sala de aula, já na Cidade Universitária, eu reagi, protestei violentamente e fui preso. Passei por várias prisões, mas sempre por pouco tempo. Foram mais detenções do que prisões. De cada vez passei umas poucas horas preso. E havia também o inconveniente da atuação política do meu filho, que estava na guerrilha.

Mas em nenhum momento o curso chegou a ser fechado. Pelo visto, eles queriam manter o curso aberto, não queriam um escândalo. Havia o problema das relações com a União Soviética, era uma situação ambígua. O nosso curso foi o único que se manteve; quando houve o golpe de 64, havia vários cursos de russo em universidades brasileiras, mas o nosso foi o único que resistiu.

P. Nessa época, quem eram os professores do curso? O senhor trabalhava sozinho?

R. Durante muito tempo, fiquei sozinho. Havia dificuldades de verba, foi muito difícil. Cheguei a dar 24 horas de aulas por semana. Depois consegui contratar assistentes. Tive vários assistentes, inclusive, dois assistentes que eram pessoas de grande valor já faleceram - Sophia Angelides e Paulo DalRi Peres. Foi realmente uma pena, porque eram pessoas muito capazes. Sophia Angelides deixou dois livros, publicados só depois da morte dela os dois são de correspondências de Tchékhov, pela Edusp, um de cartas sobre poética e o outro sobre a correspondência com Górki. Paulo Dal-Ri Peres chegou a publicar alguma coisa, mas ambos deram muito menos do que era de esperar. Morreram prematuramente. 
P. Atualmente o curso de russo da USP passa por uma fase boa.

R. É verdade. Foi possível trazer uma professora russa e professores visitantes. Também há maior possibilidade de viajar para a Rússia. Então as coisas melhoraram, sem dúvida alguma. Eu fico contente com isso. A publicação dessa revista também é um fato muito positivo.

Nos velhos tempos, o contato era mais difícil. No período da repressão mais feroz no Brasil eu estive na União Soviética, em 1972. E lá fui visitar a Instituição que lidava com intercâmbio de livros com o exterior. A gente mandava livros a eles, eles mandavam a nós, tanto é que, na nossa biblioteca, temos centenas de livros que foram conseguidos dessa forma. Eu me lembro de que nos sentamos numa mesa e começamos a conversar. Pedi que eles não nos mandassem livros com foice e martelo. Mas foi o mesmo que pedir o contrário, porque continuaram enviando livros com foice e martelo. E eu tinha problemas aqui. Depois que instituíram a censura prévia, eu tinha, de receber os livros lá nos correios, tinha de comparecer lá com carteira de identidade e pagar uma taxa pela armazenagem dos livros. Hoje em dia, isso é inconcebível.

P. Em Os Escombros e O Mito, o senhor traça um panorama da cultura russa pouco antes e depois da dissolução da URSS. Qual a sua opinião sobre as mudanças ocorridas? Qual será o caminho da cultura e literatura russa?

R. É muito difícil dizer. Eu não tenho lido o suficiente, mas tenho visto coisas bem interessantes. Houve o fato de surgir à luz do dia toda uma literatura escondida, uma coisa extraordinária. Outro exemplo positivo é a chegada, ao Brasil, de um cinema praticamente desconhecido, o cinema de Sokúrov. Essas coisas não acontecem isoladamente. Podemos esperar muito da Rússia. 